\title{
GESTÃO DE ESCOLA PÚBLICA: ANÁLISE DE UMA PROPOSTA DE INTERVENÇÃA
}

\author{
ANGELA MARIA MARTINS \\ Fundação Carlos Chagas e Programa de Pós-Graduação em \\ Educação da Universidade Católica de Santos \\ amartins@fcc.org.br
}

\begin{abstract}
RESUMO
Este texto procura aprofundar a perspectiva de análise sobre o campo de tensão constituído no espaço escolar por dois movimentos: a. os processos de ressignificação, de releitura ou de reinterpretação do conjunto normativo e legal por parte de professores, diretores e coordenadores de escolas públicas; b. as formas de apreensão destes sobre o exercício da docência e da gestão, considerando-se os contextos nos quais são formados e exercem a profissão. Partiu-se do pressuposto que, nesse espaço, as relações de trabalho são constituídas por um tripé: a. o conjunto legal e normativo (previsível e relativamente estável, tendo em vista que sua modificação requer processos de negociação política e/ou troca nas esferas executivas); b. as regras informais configuradas e negociadas entre os pares cotidianamente diante de situações reais de trabalho (imprevisíveis); c. os fatores sociais e econômicos que formam um campo cada vez mais imprevisivel de práticas singulares, tendo em vista o aprofundamento da crise social, econômica e de valores que permeiam o capitalismo contemporâneo.

ESCOLAS PÚBLICAS - GESTÃO - EDUCAÇÃO CONTINUADA
\end{abstract}

\section{ABSTRACT}

PUBLIC SCHOOL MANAGEMENT: ANALYSIS OF AN INTERVENTION PROPOSAL. The aim of this text is to broaden the perspective of the analysis of a tension area that has emerged in the school environment, by means of two movements: a. the resignification, rereading or reinterpretation processes of the set of rules and regulations by teachers, principals, and coordinators of public schools; b. the way they apply such processes to their teaching and management practices, considering the contexts in which they have been educated and practised their profession. It was assumed that in such setting working relationships are established on one tripod: a. the set of laws and regulations (predictable and relatively stable, given that their modification requires political negotiation processes and/or changes in the executive sphere); b. the informal regulations which are set and negotiated among counterparts on a daily basis in face of real work situations (unpredictable); c. the social and economic factors that determine an increasingly unpredictable area of unique practices given the deepening of the social, economic and value crisis which pervade contemporary capitalism.

PUBLIC SCHOOL - MANAGEMENT - CONTINUOUS EDUCATION 
Este texto está baseado em investigação que deu prosseguimento a estudos nos quais se buscava questionar as práticas de resistência de educadores diante de diretrizes, programas e projetos de governo (Martins, 1996)'; compreender a trama institucional, no espaço escolar, nos processos de constituição da autonomia desses profissionais e da escola (Martins, 200 I ) ; implementar intervenções em escolas públicas de ensino na rede estadual paulista (Martins, 2005a)3.

Dando seqüência a esses estudos, buscou-se aprofundar a perspectiva de análise sobre o campo de tensão constituído no espaço escolar por dois movimentos: a. os processos de ressignificação, de releitura ou de reinterpretação do conjunto normativo e legal por parte de professores, diretores e coordenadores de escolas públicas; b. as formas de apreensão destes sobre o exercício da docência e da gestão, considerando-se os contextos nos quais são formados e exercem sua profissão. Dessa forma, tomou-se por pressuposto que, nesse espaço, as relações de trabalho são constituídas por um tripé: a. o conjunto legal e normativo (previsível e relativamente estável, tendo em vista que sua modificação requer processos de negociação política e/ou troca nas esferas executivas); b. as regras informais configuradas e negociadas entre os pares cotidianamente diante de situações reais de trabalho (imprevisíveis); c. os fatores sociais e econômicos que formam um campo cada vez mais imprevisível de práticas singulares, tendo em vista o aprofundamento da crise social, econômica e de valores que permeiam o capitalismo contemporâneo ${ }^{4}$.

I. O estudo investigou as práticas de resistência de educadores diante de processos de mudança institucional. A pergunta principal que nele se procurou responder foi: por que os educadores resistem, têm dificuldades para aceitar novas orientações pedagógicas, ou, ainda, dissimulam a própria aceitação e/ou resistência.

2. A pesquisa de doutorado discutiu de que forma a implementação de programas governamentais pode (ou não) se transformar num ritual de cumprimento de normas burocráticas, resultando em uma tensão que dificulta à escola reconstruir sua dinâmica de funcionamento. Propôs-se uma investigação que buscasse compreender de que maneira a direção de uma escola de ensino fundamental e médio ressignifica as diretrizes oficiais de governo, no exercício da preconizada autonomia financeira, administrativa e pedagógica.

3. A pesquisa de intervenção Formação Continuada e Política Educacional: Trabalho e Cotidiano, foi implementada no âmbito do Programa de Pós-Graduação em Educação - PPGE - da Universidade Católica de Santos - Unisantos -, coordenada por Angela Maria Martins e contou com a participação das professoras Maria Amélia Santoro Franco e Maria de Fátima Barbosa Abdalla.

4. A pesquisa Gestão de escolas: políticas e práticas, está sendo desenvolvida no PPGE da Unisantos, no âmbito do grupo de pesquisa 


\section{A INVESTIGAÇÃO E SEU TRAJETO METODOLÓGICO}

A pesquisa de intervenção realizada em 2004/2005, em escolas estaduais localizadas na Baixada Santista (São Paulo), teve continuidade com base no acompanhamento de diretores de escolas, responsáveis pela implementação de projetos de formação continuada. Na sua primeira fase (implementação das atividades de intervenção), os pressupostos teórico-metodológicos que orientaram a pesquisa estavam referenciados em Lapassade (2005) e em Lapassade e Lourau (1972). Estes autores já apontavam, no final dos anos 1960, a importância desta metodologia no âmbito do estatuto teórico da Sociologia e da prática dos sociólogos. Segundo os autores,

...uma organização - universidade, fábrica, associação cultural - recorre a sociólogos. Estes empreendem um processo de intervenção que pode implicar, em determinado momento de seu transcurso, o emprego do questionário, da sondagem, de recursos de todas as espécies, individuais ou coletivos. (Lapassade, Lourau, 1972, p.39)

Porém, estes autores apontam, ao mesmo tempo, uma das principais limitações que podem ocorrer nesse tipo de pesquisa: os problemas a serem solucionados estão restritos à organização analisada, portanto, a experiência e seus resultados não podem ser generalizados a outras instituições sociais, ou à sociedade como um todo. Para eles, a noção de intervenção foi colocada em primeiro lugar pelos psicossociólogos no contexto da pesquisa ação, pesquisa ativa, tal como pensada por Kurt Lewin.

A intervenção transformadora no campo social deve constituir uma situação de análise, com a utilização de diversas técnicas: entrevistas de aprofundamento, entrevistas não diretivas, discussões de grupo, mas

.... essencial não é isto [...] consiste no fato de que em cada fase comunica-se à coletividade um diagnóstico que se estabelece progressivamente. Essa comunicação cria então uma situação nova, serve de reflexão e começa a modificar as comunicações entre os membros da coletividade... (Lapassade, Lourau 1972, p.4I) 
O papel do pesquisador nesse tipo de trabalho será o de tentar modificar a dinâmica de determinado grupo, com o total consentimento deste, tendo em vista as mudanças pretendidas. Nesse caso, assume dois papéis: insere-se no grupo ao mesmo tempo como participante e como profissional da ciência.

Nos anos 1980, Touraine (1982) questionava, também, as formas de movimentos que se constituem no interior das sociedades pós-industriais (completamente diferentes dos movimentos operários), fenômeno que passou a exigir novos caminhos de intervenção sociológica, em campos que poderiam ser explorados de modos diferentes: a conduta de dirigentes de organizações públicas e privadas; condutas políticas e organizacionais no âmbito de grandes organizações empresariais, de educação, de saúde etc. Para o autor, a intervenção sociológica poderia suprir lacunas para aqueles que desejam investigar a maneira de uma sociedade reproduzir a si própria, os seus modelos culturais e as suas relações sociais, pois

...hoje não podemos mais acreditar que uma organização possa ser comandada por princípios científicos; tampouco acreditamos que, pelo menos nessas sociedades, ela seja somente a obra de uma dominação central (...). somente a intervenção ativa e pessoal do pesquisador, ao puxar o ator para as relações mais fundamentais nas quais se acha envolvido, permitirá que ele deixe de se definir como respondente da ordem estabelecida e passe a agir sobre ela para modificála. (Touraine, 1982, p.38)

O autor continua assinalando a importância de se analisar o funcionamento de "pequenos grupos" em determinadas circunstâncias específicas tais como a célula política, as comunidades religiosas, as associações locais etc., tomando-se como referência que as relações ali estabelecidas são historicamente construídas, e não meras relações interpessoais. Acrescentaríamos, ainda, a importância de se analisar a participação de atores sociais em órgãos colegiados regionais, locais e no âmbito das próprias instituições (comissões, conselhos de classe e de escola, colegiados etc.). Touraine reconhece que a intervenção seria uma possibilidade de não se separar

...um caminho de pesquisa nas ciências humanas das razões históricas e sociais que as fizeram surgir. Não é contraditório afirmar que a intervenção sociológica 
tem um valor humanístico e reconhecer que ela é, também, o signo de um desejo de fazer renascer uma consciência da história, e assim defender e reforçar as chances da democracia. (1982, p.45)

Embora essa visão sociológica esteja relacionada à necessidade de se repensar formas de pesquisar os movimentos sociais que eclodiram desde meados dos anos 1970, na França, sua contribuição, em alguns aspectos, ainda é fundamental no que diz respeito a propostas de intervenção em organizações ${ }^{5}$.

Nesse sentido, a pesquisa de intervenção realizada entre 2004 e 2005, adotou tais pressupostos teórico-metodologicos para trabalhar com coordenadores pedagógicos de 30 escolas da rede estadual paulista ${ }^{6}$. Na seqüência, analisamos o campo de tensão constituído na dinâmica escolar, no âmbito das atividades implementadas pelo projeto de formação continuada, com base na atuação de diretores de escolas, responsáveis por sua articulação. Na segunda fase da pesquisa, não ocorreram, portanto, mais intervenções. Buscou-se um desenho metodológico mais flexível, que pudesse incorporar e tomar como base os resultados anteriores. Estudos com desenhos mais flexíveis têm sido adotados na área de ciências humanas e sociais. Corcuff (200 I, p.8), ao analisar os conceitos trabalhados pela sociologia francesa nos anos 1980 e 1990, assinala que apesar das divergências e disputas travadas em torno de diferentes correntes, alguns autores apresentam certa convergência (um processo ainda em movimento) devido às trocas interdisciplinares (sociologia/filosofia/ ciência, política/história/lingüística etc.) e à recusa em aceitar os famosos pares de conceitos (das clássicas antinomias): material/ideal, objetivo/subjetivo; coletivo/individual, macro/micro. Por discordarem dessas esterilizantes oposições, muitos teóricos desenharam "pouco a pouco um novo espaço de questões e de problemas que escolhemos chamar de construtivismo social”.

5. Touraine propõe esse tipo de intervenção sociológica com base em sua experiência na greve estudantil de 1976, com o movimento antinuclear e o movimento occitano na França.

6. O estudo original atendeu a demandas regionais, sistematizadas pela própria Diretoria Regional de Ensino de Santos, que vislumbrou, naquele momento, a possibilidade de participar como instituição de um processo compartilhado de construção de formação continuada que pudesse constituir, ao mesmo tempo, um percurso de pesquisa. A dirigente, então, era Mariângela Camba de Almeida. 
De acordo com Corcuff (200I), um esquema clássico em filosofia (adotado posteriormente pela sociologia) é aquele que coloca em cena um sujeito diante de um mundo de objetos e, nesta oposição, ambas as noções passam a ser identificadas. As variações semânticas do termo "objetivo" foram consolidadas em torno das seguintes idéias: a. quando aparece oposto a subjetivo, se referindo a uma realidade que subsiste nela mesma, independente de qualquer idéia ou conhecimento; b. quando aparece também oposto a subjetivo, no sentido de ser válido para todos e não somente para um indivíduo; c. quando aparece oposto a subjetivo no sentido de método de observação exterior ao objeto observado. Nesse sentido o autor sublinha que essas variações semânticas aparecem, da mesma forma como outros tradicionais pares de conceitos, tais como individual/coletivo; voluntário/involuntário; consciente/inconsciente; exterior/interior. Apoiando-se em Bourdieu ${ }^{7}$, o autor sublinha que o objetivismo estabelece regularidades estruturais (sistemas de relações) independentes das vontades individuais e das consciências, isto é, centra sua análise sobre os fenômenos sociais no olhar exterior a eles. Em outras palavras, ainda, o objetivismo apresenta o mundo exterior como um espetáculo para o qual o observador (pesquisador) deve olhar, assumindo seu ponto de vista sobre a ação, dando-Ihe, por conseqüência, uma posição fixa e homogênea. Ao contrário dessa perspectiva, "a postura subjetivista tomaria sobre a ação os pontos de vista dos sujeitos agentes" (Corcuff, 200 I, p. 18).

Na visão desse autor, os sociólogos que desejam desenhar outros percursos terão de se dedicar, no plano conceitual, à análise das relações entre os aspectos objetivos e subjetivos da realidade social e, no plano de construção do próprio objeto, terão que "estabelecer passagens entre o ponto de vista exterior do observador sobre o que ele observa e as maneiras como os observadores percebem e vivem o que fazem no curso de suas ações" (Corcuff, 2001 , p. 19), isto é, deverão utilizar-se de uma reflexão sociológica, integrando, portanto, ao processo de construção do objeto, uma reflexão sobre sua própria relação com o objeto. Nas palavras de Bourdieu:

7. Pierre Bourdieu, Norbert Elias e Anthony Giddens, inseridos em tempos e lugares diferentes, são considerados três pensadores que deram certa predominância às estruturas e aspectos macrossociais, embora buscassem integrar as dimensões subjetivas e interacionais. 
...para resumir a relação complexa entre as estruturas objetivas e as construções subjetivas, situada além das alternativas comuns do objetivismo e do subjetivismo, do estruturalismo e até do materialismo e do idealismo, costumo citar, deformando-a ligeiramente, uma fórmula célebre de Pascal: "o mundo me contém e me engole como um ponto, mas eu o contenho". O espaço social me engloba como um ponto. Mas esse ponto é um ponto de vista, princípio de uma visão assumida a partir de um ponto situado no espaço social, de uma perspectiva definida em sua forma e em seu conteúdo pela posição objetiva a partir da qual é assumida. $\bigcirc$ espaço social é a realidade primeira e última já que comanda até as representações que os agentes sociais podem ter dele. (2005, p.27)

Corcuff (200l , p.65) assinala as contribuições da sociologia reflexiva de Bourdieu ${ }^{8}$ e também aponta sua negligência em relação aos processos interativos, e a primazia dada em sua obra às estruturas e à objetividade da realidade, o que faz recuperar, ao longo de sua produção, "o par aparência/realidade, que tenderia a afastar sua sociologia do universo construtivista".

A discussão realizada por Corcuff ao apresentar e debater as correntes mais recentes do pensamento social, é salutar na medida em que traça um interessante painel sobre as divergências e semelhanças que rondam os problemas atuais em sociologia. Em suas origens, a sociologia estabeleceu a primazia das questões coletivas em detrimento das questões individuais e, desde aí, tem-se debatido com essas relações. $\bigcirc$ individualismo metodológico ${ }^{9}$, ao criticar a predominância dessa visão, proclamou ser indispensável reconstruir as motivações dos indivíduos quando envolvidos em situações de grupamentos (Haguette, 2005). Contra essa oposição binária, as ciências sociais mergulham na polêmica em busca das possíveis mediações entre as estruturas (macrossociais) e as ações individuais, tramadas no cotidiano.

8. O trabalho de auto-socioanálise é fundamental para que o pesquisador examine seu lugar no campo intelectual, sua trajetória (de idéias), seu percurso de vida etc.

9. Alguns autores se referem aos termos individualismo metodológico, abordagem da escolha racional e economia neoclássica como se fossem intercambiáveis. No entanto, as divergências existentes não são apenas semânticas. Há divergências, inclusive, em relação ao individualismo metodológico, visto por alguns autores como aliado também à noção históricoestrutural vinculada ao marxismo. Ver Haguette (2005). 
Nessa perspectiva, a segunda fase do estudo partiu do pressuposto que, no espaço escolar, as relações de trabalho são constituídas pelo conjunto legal e normativo - estruturadas em contextos sociais, econômicos e culturais -, e por regras configuradas e negociadas entre os pares cotidianamente diante de situações reais de trabalho, construindo um campo de práticas sociais singulares.

\section{CENÁRIO DA PESQUISA}

Compõem a Diretoria de Ensino de Santos quatro municípios: Bertioga, Cubatão, Guarujá e Santos. Este universo compreende 77 escolas que congregam 92.649 alunos. A diversidade social e econômica entre os municípios é grande e, conseqüentemente, a infra-estrutura urbana também é diversificada. Observou-se, num primeiro momento, com base no diagnóstico socioeconômico realizado nas 30 escolas, que uma parte delas estava localizada em áreas carentes e não era, portanto, atraente para os professores recém-concursados e bem classificados no concurso da Secretaria da Educação do Estado de São Paulo, em 2003. Os professores que assumiram aulas nessas escolas apresentavam um perfil repleto de carências culturais e de formação em suas respectivas áreas.

Das unidades, 12 lidavam com dificuldades administrativas, burocráticas e financeiras de tal ordem que impediam a resolução de quaisquer problemas, desde a assinatura de revistas ou jornais até a impossibilidade de manutenção dos equipamentos escolares (televisões; vídeos). As demais escolas ( 8 ) estavam localizadas em regiões socioeconômicas privilegiadas, o que thes possibilitava ter uma comunidade mais atuante: os pais participavam mais das atividades intramuros escolares, dos órgãos colegiados ou de "festas de arrecadação de recursos" para manutenção da própria infra-estrutura do prédio (pinturas; jardins; equipamentos hidráulicos; equipamentos audiovisuais). Da mesma forma, também estavam mais presentes nas reuniões para discussões sobre questões pedagógicas, o que criava certa pressão sobre as equipes de direção.

O desenvolvimento do curso de formação continuada e da própria pesquisa, em sua primeira fase, tomando como locus as unidades escolares, constituiu uma inovação quanto aos procedimentos usuais de capacitação, ofertados pela Secretaria de Educação do Estado de São Paulo, de modo geral, elaborados por equipes técnicas alocadas na própria Secretaria, e/ou por professores 
universitários que assumem o papel de assessores para essas atividades. Essa inovação provocou mudança substancial no relacionamento entre a equipe de pesquisadores, o órgão responsável pela parceria (a Diretoria de Ensino Regional), e os coordenadores pedagógicos e diretores das escolas envolvidas.

As escolas que participaram podem ser agrupadas em três situações: o Grupo I, composto por cinco unidades, cujos professores apresentaram resistência em desenvolver as atividades propostas pelos coordenadores pedagógicos (desdobramentos de sua participação no curso de formação continuada e na pesquisa). $\bigcirc$ Grupo 2, composto por sete escolas, que apresentaram um perfil mais acomodado ao cumprimento das atividades, sem demonstrar maiores preocupações no que diz respeito ao aprofundamento das discussões no âmbito escolar, que possibilitasse instaurar um processo de reflexão sobre seus problemas e indicar, coletivamente, as mudanças necessárias para contorná-los. Finalmente, o Grupo 3, composto pela maioria das escolas ( I 8), cujos professores participaram intensamente tanto nas atividades propostas por seus coordenadores, decorrentes do curso de formação continuada, quanto nas atividades de registro em diários que faziam parte da pesquisa de campo, desenvolvida no espaço escolar. Houve incentivo à participação de alunos, inclusive, em novos projetos gestados no percurso deste trabalho.

Na primeira fase, professores-coordenadores de escolas do grupo I, afirmaram que sentiam dificuldades para realizar as atividades propostas para as horas de trabalho pedagógico - HTPs. Intervenientes impostos por diretores e vice-diretores de algumas dessas escolas e a ausência de interesse de professores nas atividades das HTPs foram as respostas mais apontadas. $\mathrm{Na}$ segunda fase, observou-se que, em alguns casos, os diretores não tiveram uma postura abertamente proibitiva em relação às reuniões para discussão das atividades propostas, simplesmente não facilitaram aos coordenadores a articulação das atividades dentro da escola por diferentes motivos apontados: ausência de suporte financeiro para o desenvolvimento de algumas atividades; ausência de suporte administrativo; falta de pessoal de apoio (número insuficiente de funcionários para "tomar conta do pátio", tendo em vista que algumas atividades exigiam a saída de alunos da sala de aula).

Sem o aval e a parceria da figura do diretor que, para todos os efeitos, ainda detém fundamental importância no âmbito da articulação dos trabalhos escolares, as atividades dessas cinco escolas se resumiam a relatos parciais de lei- 
turas realizadas sobre os textos indicados. $\bigcirc$ medo, a insegurança e os riscos de assumirem atividades sobre as quais não detinham domínio de conteúdos, tiveram como aliada a completa ausência de incentivo de diretores que, baseados em aspectos legais e formais, afirmavam ser "difícil compatibilizar o horário de professores nas [horas de trabalho pedagógicas coletivas] HTPCs, ainda sem dizer que eles já têm tarefas agendadas desde o início do semestre" (Carlos) ${ }^{10}$.

Marcos também afirmou que "desenvolver certas atividades fora da sala de aula, é impossível, porque atrapalha as outras classes" e que "está difícil porque a Secretaria da Educação exige o desenvolvimento de 'n' projetos, com prazos pra cumprir etc.", o que não constitui exatamente a realidade. Há, realmente, forte demanda da Secretaria de Estado da Educação de São Paulo desde fins dos anos 1990, principalmente, para que as escolas desenvolvam projetos alternativos e/ou especiais. No entanto, não há indícios de que essa demanda tenha provocado mudanças na atuação das escolas, no sentido de que estejam cumprindo metas e prazos rigorosos.

Pode-se afirmar, com certa tranqüilidade, que o perfil de gestão dessas cinco unidades é burocrático-racional. Não se trata, neste texto, de entrarmos na discussão sobre a polissemia da palavra burocracia, muito menos de entrarmos na seara dos teóricos que disputam o entendimento do legado weberiano, no que tange à constituição de modelos teóricos das organizações. Concordamos com Lima, quando este analisa os modelos teóricos de organização escolar e afirma que

...a carência de estudos organizacionais e sociológicos da escola como organização, a falta de conhecimento dos modos de organização não exclusivamente formal e a própria tradição centralista-burocrática, transformada em convicção e em teoria explicativa sem exame teórico e empírico, justificarão provavelmente uma fixação no plano das orientaçães e a redução deste à dimensão jurídica e formal. (2003, p.4I)

Nesse sentido, o autor critica os modelos teóricos baseados na concepção burocrático-racional para analisar instituições educativas e aponta a neces-

10. Nomes fictícios. 
sidade de que essa perspectiva jurídica, normativa e legal, muitas vezes produzida pela própria administração central, seja confrontada com as práticas dos atores "com as estratégias levadas a cabo por grupos e subgrupos nas organizações". De qualquer forma, este estudo procurou analisar tais práticas, o que não impede de detectar nas escolas a prevalência de um perfil de gestão burocrático e excessivamente formal.

Uma outra perspectiva auxilia também na compreensão desse perfil: a visão do professor e do diretor como sujeitos "executores", no entanto, com certa autonomia no espaço escolar. Baseados em David e Payeur, Tardiff e Lessard (2005, p.79) afirmam que essa dupla posição - de executantes e autônomos - "se traduz também em tensões e dilemas, podendo, conforme invistam em um outro pólo (execução ou autonomia), desembocar em diferentes maneiras de assumir e viver sua identidade profissional". Neste caso, os diretores das escolas configuraram um contexto normatizador e previsível, exercendo o papel de executores de horários e cumprindo, apenas formalmente, o ritual de "atendimento" a projetos enviados pela Secretaria de Estado da Educação" . O imprevisível - o que não estava formalmente previsto por orientações legais/formais, isto é, o desenvolvimento de atividades complementares discutidas e vivenciadas por seus coordenadores em situação de formação continuada - foi ignorado e ampliou a sensação de insegurança dos coordenadores na construção de sua identidade e no exercício de sua função. Conforme assinala Lima

...na escola, [...] ora se ligam objectivos, estruturas, recursos e actividades e se é fiel às normas burocráticas, ora se promove a sua separação e se produzem regras alternativas; ora se respeita a conexão normativa, ora se rompe com ela e se promove a desconexão de facto ${ }^{12}$. (2003, p.62)

No que tange ao Grupo 2 (sete escolas), verificou-se que os coordenadores pedagógicos estavam mobilizados para cumprir apenas a formalidade dos

I I. Na realidade, o atendimento se limitava à formalização da inclusão de alguns conteúdos que diziam respeito aos "temas" dos denominados projetos especiais: meio ambiente; higiene etc.

12. Pode-se pensar, em outra perspectiva, com Bourdieu (2005), que o funcionário público representa o pensamento oficial e é por ele atravessado. 
objetivos apresentados quando do início das intervenções. Em resumo, buscavam o cumprimento estrito das atividades propostas em suas unidades e, provavelmente, procuravam responder às expectativas postas nas discussões realizadas inicialmente com os demais coordenadores e com a equipe de professores da universidade. Os depoimentos deixavam transparecer que havia problemas de relacionamento entre professores, equipes de direção e coordenação, ao se instaurar certa disputa em torno das atividades relacionadas ao projeto.

Essa disputa expressava, na realidade, relações de grupos e de subgrupos que representavam interesses diferentes dentro da escola: os mais próximos do(a) diretor(a); os mais próximos do(a) coordenador(a); os mais próximos dos professores que exercem liderança na escola. Esse campo de tensão, no qual as disputas de interesses diferentes apareciam de forma sub-reptícia, leva a refletir com Bourdieu:

...os seres aparentes, diretamente visíveis, quer se trate de indivíduos, quer de grupos, existem e subsistem na e pela diferença, isto é, enquanto ocupam posições relativas em um espaço de relações que, ainda, que invisível e sempre difícil de expressar empiricamente, é a realidade mais real (....) e o princípio real dos comportamentos dos indivíduos e dos grupos. (2005, p.49)

Na visão do autor, esse jogo de interesses diferentes indica que os agentes fazem o que fazem porque

...todo campo social, seja o campo científico, seja o campo artístico, o campo burocrático ou o campo político, tende a obter daqueles que nele entram essa relação com o campo que chamo de illusio. Eles podem querer inverter as relações de força no campo, mas, por isso mesmo, reconhecem os alvos, não são indiferentes $[\ldots]$ entre pessoas que ocupam posições opostas em um campo, e que parecem radicalmente opostas em tudo, observa-se que há um acordo tácito e oculto a respeito do fato de que vela a pena lutar a respeito das coisas que estão em jogo no campo. $\bigcirc$ apolitismo primário, que não cessa de crescer, já que o campo político tende cada vez mais a fechar-se sobre si mesmo e a funcionar sem se referir à clientela [...], apóia-se sobre uma espécie de cons- 
ciência confusa dessa cumplicidade profunda entre os adversários inseridos num mesmo campo: eles se enfrentam, mas estão de acordo pelo menos a respeito do objeto de desacordo. (2005, p. I4I)

Nas escolas do Grupo 3 as atividades foram realizadas devido ao esforço coletivo de equipes envolvidas, cujos profissionais demonstraram certa desenvoltura para refletir e agir sobre as proposições de um projeto com essas características, sentindo-se inclusive à vontade para desnudar seus limites e propor saídas alternativas para as dificuldades encontradas. Nessas escolas, ao que tudo indica, a articulação do trabalho do diretor, do vice-diretor e da própria coordenação pedagógica estava baseada em uma amplitude de princípios que respeitava as diferentes formações, experiências de vida e trajetórias profissionais, sendo o elemento preponderante para que as dificuldades fossem transpostas e as atividades realizadas coerentemente com as necessidades de suas comunidades.

Nessas unidades, a maioria dos professores e coordenadores pedagógicos se interessou em aprofundar seus conhecimentos, procurando outras formas de ensinar e de avaliar os alunos (dois participantes do processo, inclusive, prosseguiram cursando mestrado em educação, incentivados pela participação no projeto). Para tanto, registraram todos os problemas e possíveis caminhos alternativos de saída, em diários de campo. Em artigo anterior, discutíamos porque algumas escolas se aproveitam de reformas do sistema de ensino, de propostas de inovação pedagógica ou de incentivos oficiais, para produzirem mudanças em suas práticas pedagógicas, construindo uma nova dinâmica nos processos de gestão escolar. Pensamos que isso pode ser possível porque, de um lado, tais instituições tiveram sua ação centrada na negociação e na regulação contínuas que todo processo de mudança institucional permite, e de outro, porque seus profissionais se posicionam como atores coletivos em relação ao sistema.

Na referida análise, perguntávamos quais fatores endógenos haviam sido necessários para que essas escolas contornassem algumas de suas dificuldades e conseguissem se organizar em torno de idéias comuns? Podemos recorrer à mesma indagação, neste caso, pois estas escolas do Grupo 3 apresentavam algumas condições de similaridade que parecem oferecer notícias das fontes motivadoras de transformação do cotidiano escolar: possuíam equipes de di- 
reção (diretores, vice-diretores e coordenadores pedagógicos) envolvidas com o corpo docente, discente e comprometidas com a comunidade; vêm tentando construir uma trajetória em defesa da melhoria da escola pública; os professores se envolveram em processos internos de negociação compartilhada e procuraram concretizar as atividades inovadoras para renovar as práticas pedagógicas de suas unidades; possuíam um quadro estável de professores e equipes de direção que se colocaram em processo de auto-análise.

Curiosamente, em relação à avaliação da dinâmica geral das atividades de intervenção, a maioria dos diretores afirmou (28 escolas) que estas haviam permitido um crescimento profissional e pessoal dos coordenadores envolvidos e de professores que se integraram ao processo de formação contínua nas escolas. Na afirmação de Luís, "houve a compreensão de novas possibilidades e metodologias de trabalho [...] percebemos que nossos coordenadores voltavam para a escola trocando idéias com outros colegas...". Enfatizaram, ainda, que o projeto diminuía a sensação de isolamento que sentiam em suas escolas.

Esses depoimentos poderiam questionar as contradições detectadas ao longo do percurso, conforme se analisou. No entanto, diretores, coordenadores e professores decidiram espontaneamente participar do projeto de intervenção. Trabalharam instaurando um processo de reelaboração de suas atividades, o que pode ter provocado a sensação de insegurança em relação às suas bases de conhecimento da prática cotidiana. A situação não é confortável no exercício de nenhuma profissão. Muitas das contradições e conflitos que vivenciamos podem ter advindo desse momento de incertezas.

De qualquer forma, não houve desistência de nenhum participante e todos se esforçavam na reconstituição permanente das atividades, formando um grupo com interesses que, apesar de divergentes, possuíam um ponto em comum: a busca de soluções que afligiam aqueles profissionais no cotidiano de trabalho.

\section{BREVES CONSIDERAÇÕES FINAIS}

Embora tenha sido possível verificar algum grau de dissimulação, certa persistência de comportamentos consagrados pela cultura escolar (esperar que outros façam por mim; tomem iniciativas; permitam que eu faça etc.), e alguma resistência diante das atividades propostas (praticada pelos próprios coor- 
denadores e/ou pelas equipes de direção das unidades), os atores envolvidos se defrontaram com a necessidade de discutir divergências, limites, formação profissional e de questionar as práticas pedagógicas, em outras palavras, "jogaram o jogo". Na visão de Bourdieu (2005, p. I 40) "podemos estar interessados em um jogo (no sentido de não lhe ser indiferentes), sem ter interesse nele. O indiferente não vê o que está em jogo, para ele dá na mesma"|3.

Explicitaram o sofrimento e as angústias do cotidiano, diante da insegurança de exercer uma

...profissão impossível, que flerta todos os dias com os limites da ação humana sobre outrem, (o que) requer uma certa solidez mental. $O$ fracasso escolar e a impossibilidade de instruir todo mundo criam uma forma de sofrimento próprio às profissões que lidam com seres humanos, que existe também entre os enfermeiros e os assistentes sociais. (Perrenoud, 2005, p.42)

No entanto, a profissão só se torna verdadeiramente um sofrimento

...quando os profissionais têm a impressão de que é uma organização que os impede de trabalhar ou provoca uma sobrecarga, devido a reformas apressadas, decisões arbitrárias, falsas respostas, investimentos que não correspondem às verdadeiras necessidades, disputas administrativas, injunções paradoxais. (Perrenoud, 2005, p.42)

O desenvolvimento de atividades de intervenção propostas na primeira fase do estudo em pauta, alterou o sentido das formações continuadas, de modo geral ofertadas por programas oficiais, em que a possibilidade de expressão das singularidades dos profissionais envolvidos é muito pequena ou quase

13. Bourdieu (2005, p. |40) esclarece sua noção de interesse, diferente de desinteresse e de indiferença. Nas palavras do autor "a illusio é [...] estar envolvido, é investir nos alvos que existem em certo jogo, por efeito da concorrência, e que apenas existem para as pessoas que, presas ao jogo, e tendo as disposições para reconhecer os alvos que aí estão em jogo, estão prontas a morrer pelos alvos que, inversamente, parecem desprovidos de interesse do ponto de vista daquele que não está preso a este jogo [...]". 
inexistente. Ao se levar em consideração essa especificidade, as atividades propostas, discutidas, analisadas e alteradas pelos próprios atores, geraram uma trama específica que, sem dúvida, mudou o cotidiano escolar, permitindo-lhes a apropriação de um tempo apenas deles, criação híbrida para superar dificuldades e desesperanças do dia-a-dia.

De fato, o espaço escolar é constituído, de um lado, por um conjunto de regras e normas que codificam o trabalho cotidiano (previsíveis), e de outro, há um trabalho não codificado, permeado por interações dos atores escolares que improvisam bastante (imprevisíveis). Tardiff, Lessard sublinham que o trabalho dos professores pode ser visto de um ângulo administrativo, cujo modus operandi está determinado pelo conjunto legal e normativo implementado pela esfera governamental, em negociação com entidades do magistério e sindicatos. Mas também pode ser visto da perspectiva das exigências reais do cotidiano. Essas duas perspectivas traçam a distinção entre a tarefa prescrita e a tarefa real. Nesse contexto,

....alguns professores fazem exata e unicamente o que é previsto pelas normas oficiais da organização escolar, ao passo que outros se engajam a fundo num trabalho que chega a tomar um tempo considerável, até mesmo invadindo sua vida particular, as noites, os fins de semana, sem falar das atividades de duração mais longa, como cursos de aperfeiçoamento, de formação específica, atividades paraescolares ou sindicais, das associações profissionais [...] etc. (Tardif e Lessard, 2005, p.113)

O engajamento das 30 escolas no projeto significou uma sobrecarga de trabalho para todos os envolvidos. As atividades propostas para ser desenvolvidas nas escolas se somavam às atividades administrativas que ocupavam a maior parte do tempo de trabalho desses atores). A necessidade de compreender, analisar, ultrapassar o espaço escolar codificado, geralmente visto como o aspecto perverso da política educacional, pois se tem expandido inexoravelmente, fez que os diretores, coordenadores e professores buscassem inspiração no projeto para também compreenderem, analisarem e ultrapassarem as características do trabalho real, não codificado, que eles reinventam todos os dias no confronto com o contexto prescritivo. 
Acrescente-se ainda que, das 18 escolas do grupo 3, sete delas se destacaram e lograram desenhar caminhos mais sistematizados para os problemas discutidos, demonstrando, por uma série de fatores, ter mais segurança e autonomia. Estavam localizadas em regiões cujo perfil socioeconômico permitia às comunidades maior participação na vida das escolas, tanto no que diz respeito à sua manutenção, com auxílio financeiro, quanto no que tange à participação nos órgãos colegiados); possuíam corpo docente concursado e estável; possuíam professores com participação em entidades de classe; estes demonstravam interesse espontâneo de participar de outros cursos de especialização; direção, vice-direção e coordenação pedagógica compunham, efetivamente, uma equipe de gestão bastante atuante e que privilegiava as questões pedagógicas, a despeito de assinalarem a sobrecarga de trabalho administrativo.

No entanto, esses mesmos fatores configuraram também um campo de tensão, pois diretores, coordenadores e professores se viam, o tempo todo, diante de situações de conflito, tanto no que diz respeito às dificuldades inerentes aos processos interativos (professores/alunos; professores de grupos diferentes que disputam idéias, projetos, espaços; professores e direção; professores e coordenação etc.), quanto no que se refere à necessidade de ter de "desrespeitar" algumas normas oficiais (por exemplo, diretores que precisaram contornar dificuldades para liberar professores para que a discussão das atividades do projeto pudesse ser feita pelo maior número de docentes durante, as HTPCs ou em horários alternativos). Como afirma Tardiff e Lessard, esses fatores

...não somam-se, simplesmente. Eles atuam em sinergia para criar uma carga de trabalho complexa, variada e portadora de tensões diversas. Além disso, constata-se que vários desses fatores remetem a tarefas invisíveis que demandam igualmente a afetividade e o pensamento dos professores. (2005, p. I |4)

Em resumo, as atividades de intervenção tornaram visíveis situações do cotidiano escolar que nos remetem à reflexão sobre sua especificidade e complexidade no contexto contemporâneo.

Os processos interativos que ocorrem em locais de trabalho, independentemente de serem empresas, hospitais ou escolas, apenas para citar alguns, são a expressão de um conjunto de fatores configurados por regras formais/ 
legais e normativas estabelecidas em contratos sociais, mas, ao mesmo tempo, expressam as singularidades dos indivíduos envolvidos nessas situações: o conhecimento, as representações e os processos mentais do sujeito cognitivo e, também, as histórias de vida, os desejos, as personalidades, as posturas, os interesses, as emoções, enfim, o "jeito de ser" de cada um, o sujeito hermenêutico (Tardiff, Lessard, 2005).

No contexto normatizado das escolas, diretores, coordenadores e professores oscilam entre a possibilidade de serem agentes da organização e atores do cotidiano. De um lado, como agentes, eles trabalham de acordo com as regras estabelecidas pelo aparato burocrático e normativo do sistema de ensino, o que facilita o alívio de tensões por um certo distanciamento (saudável) de problemas que assolam o cotidiano cumprem horários; tarefas; calendários; avaliações e ponto final. Nas palavras de Lima (2003, p.66), "o rigor da administração coexiste, freqüentemente, com a tolerância, por mais paradoxal que possa parecer". Isso cria uma ambivalência, pois o conjunto de regras formais, ao mesmo tempo em que cerceia, garante a proteção necessária para aqueles que se resguardam atrás da legislação e da previsão de suas tarefas. De outro lado, como atores, assumem todos os riscos, tensões e contradições do exercício de uma profissão que se improvisa nesse mesmo cotidiano.

Finalmente, sabemos que toda pesquisa qualitativa instaura um processo de intenso relacionamento entre pesquisadores e pesquisados, e esta questão tem sido tratada no âmbito das discussões sobre método e metodologia de pesquisa. $\bigcirc$ controle do que comumente se chama viés nas ciências sociais não é tarefa fácil, pois pesquisadores e estudiosos têm que fazer um esforço incomum para conter preconceitos, parcialidades e empatias no decorrer de uma investigação. Não vamos entrar na seara do debate sobre pesquisas quantitativas versus pesquisas qualitativas, particularmente, sobre a possibilidade de controle de viés nos surveys $^{14}$, mas não podemos nos furtar de assinalar que, por se tratar este de um estudo de intervenção, sofremos interferências ao longo do percurso inicialmente estabelecido, o que acabou configurando um

14. Goldemberg (2004, p.46) analisa bem a questão quando sublinha o quão difícil é essa tarefa, pois se nas pesquisas quantitativas o pesquisador pode induzir ou falsificar dados, o que diríamos de pesquisas qualitativas, nas quais os pesquisadores podem (e têm) muito mais liberdade com os entrevistados, com atitudes "que vão desde sorrisos até intervenções mais diretas". 
caminho repleto de possibilidades para ambas as polaridades envolvidas: diretores, coordenadores e professores das escolas de ensino básico, e pesquisadores universitários. Compartilhamos com Goldemberg a idéia de que

....a simples escolha de um objeto já significa um julgamento de valor na medida em que ele é privilegiado como mais significativo entre tantos outros sujeitos à pesquisa. O contexto da pesquisa, a orientação teórica, o momento sócio-histórico, a personalidade do pesquisador, o ethos do pesquisado, influenciam o resultado da pesquisa. Quanto mais o pesquisador tem consciência de suas preferências pessoais mais é capaz de evitar o bias, muito mais do que aquele que trabalha com a ilusão de ser orientado apenas por considerações científicas. (2004, p.45)

De qualquer forma, acreditamos que os desafios desse trabalho diário devem nortear as preocupações dos especialistas que se têm dedicado a refletir sobre a dinâmica da gestão no espaço escolar, visualizando-o como permanente processo de construção das possibilidades e limites para reconstrução de relações mais democráticas e coerentes com as necessidades do alunado. Atividades de intervenção podem indicar caminhos diferentes na construção da reflexão conjunta e necessária, realizada por parceiros alocados em espaços sociais e simbolicamente diferentes entre si, mas que possuem um ponto de convergência fundamental: a busca da superação de problemas e limites impostos à escola por fatores exógenos e endógenos a ela.

\section{REFERÊNCIAS BIBLIOGRÁFICAS}

BOURDIEU, P. Razões práticas: sobre a teoria da ação. Campinas: Papirus, 2005.

CORCUFF, P. As Novas sociologias: construções da realidade social. Bauru: Edusc, 200 I .

GOLDEMBERG, M. A Arte de pesquisar. Rio de Janeiro: Record, 2004.

HAGUETTE, T. M. F. Metodologias qualitativas na sociologia. Petrópolis: Vozes, 2005.

LAPASSADE, G. As Microssociologias. Brasília: Liber Livro, 2005.

LAPASSADE, G; LOURAU, R. Chaves da sociologia. Rio de Janeiro: Civilização Brasileira, 1972. 
LIMA, L. C. A Escola como organização educativa. São Paulo: Cortez, 2003.

MARTINS, A. M. Gestão e autonomia da escola pública: entre a teoria e a prática. Campinas, 200 I. Tese (dout.) Universidade Estadual de Campinas.

A Gestão pedagógica e os diferentes caminhos de formação continuada: o espaço escolar em construção. In: FRANCO, M. A. S. (org.) O Lugar do professor na pesquisa educacional. Santos: Leopoldianum, 2005. p. I17-|48.

Mudança, resistência e educação: práticas profissionais e limites do Estado.

São Paulo, 1996. Dissert. (mestr.) Universidade de São Paulo.

PERRENOUD, P. Fadiga. In: PERRENOUD, P. et al. (orgs.) A Escola de A a Z. Porto Alegre: Artmed, 2005. p.4I-45.

TARDIFF, M.; LESSARD, C. O Trabalho docente: elementos para uma teoria da docência como profissão de interações humanas. Petrópolis: Vozes, 2005.

TOURAINE, A. O Método da sociologia da ação: a intervenção sociológica. Revista Novos Estudos CEBRAP, v. I, n.3, p.36-45, jul. 1982.

Recebido em: março 2006

Aprovado para publicação em: junho 2006 